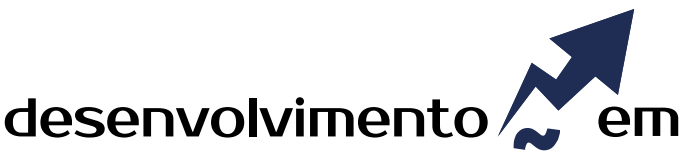 QUESTÃO
}

\section{Análise da Expansão Urbana e Perspectivas de Uso dos Espaços Públicos no Município de Francisco Beltrão-PR}

http://dx.doi.org/10.21527/2237-6453.2020.52.178-193

Recebido em: 7/5/2019

Aceito em: 18/5/2020

\author{
Vanessa Franciele de Gois, ${ }^{1}$ Nilvania Aparecida de Mello ${ }^{2}$
}

\begin{abstract}
RESUMO
O acentuado crescimento das cidades brasileiras registrado nos últimos anos resulta em constantes mudanças dos hábitos, costumes, culturas e valores sociais, requerendo atenção às necessidades dos habitantes em relação espaços públicos urbanos. Esse desenvolvimento causa mudança ao meio ambiente, comprometendo a paisagem urbana, pois as áreas públicas de lazer proporcionam qualidade de vida aos usuários. Quando planejadas pelos gestores públicos na distribuição da malha urbana, as áreas verdes têm papel importante na relação da melhoria microclimática, da ação contra a poluição, barreira acústica e conforto lumínico para aqueles que desfrutam do espaço. Este artigo faz uma análise da apropriação das praças na cidade de Francisco Beltrão/PR, identificando as suas áreas verdes. Estas análises foram feitas com o intuito de localizar com tal conhecimento as normativas municipais buscando apontar as possibilidades de um melhor uso para uma forma de vida mais ativa, explorando a arborização. Foram traçados como ferramentas de pesquisa, inicialmente, o referencial teórico e, posteriormente, os estudos de caso das praças distribuídas nos bairros da cidade, listadas pela prefeitura para validar, analisar e compreender a sua inserção no espaço. Ao final da análise relacionamos as áreas verdes para servir à requalificação em novos programas que venham a enaltecê-las.
\end{abstract}

Palavras-chave: Praças públicas. Áreas verdes. Planejamento.

\section{ANALYSIS OF URBAN EXPANSION AND PROSPECTS FOR THE USE OF PUBLIC AREAS}

IN THE MUNICIPALITY OF FRANCISCO BELTRÃO-PR

\begin{abstract}
The sharp growth of Brazilian cities registered in recent years incurs constant changes in habits, customs, cultures and social values, requiring attention to the needs of inhabitants in urban public spaces. This development causes change to the environment, compromising the urban landscape because public leisure areas provide quality of life to users when planned by public managers in the distribution of the urban network, green areas have an important role in the relationship of microclimate improvement, of action against pollution, acoustic barrier and light comfort for those who enjoy the space. The article implements an analysis of the appropriation of the squares in the city of Francisco Beltrão/PR, identifying its green areas. These analyzes were made in order to locate with such knowledge of the municipal regulations seeking to point out the possibilities of a better use for a more active way of life exploring the afforestation. The theoretical framework was designed as research tools, initially, and later, the case studies of the squares distributed in the city's neighborhoods, listed by the City Hall to validate, analyze and understand. At the end of the analysis, we list its green areas to be used for the requalification in new programs that will enhance it - there.
\end{abstract}

Keywords: Public squares. Green areas. Planning.

\footnotetext{
${ }^{1}$ Graduada em Arquitetura e Urbanismo pela Universidade do Vale do Itajaí (Univali). Aluna do curso de Mestrado em Desenvolvimento Regional pela Universidade Tecnológica Federal do Paraná (UTFPR). http://lattes.cnpq.br/5611307744390325. https://orcid.org/000-00018824-0081 arquiteturaurb.vanessa@gmail.com

2 Doutora em Ciência do Solo Pela Universidade Federal do Rio Grande do Sul (UFRGS). Professora da Universidade Tecnológica Federal do Paraná (UTFPR). http://lattes.cnpq.br/0041964058612806. https://orcid.org/ 000-0002-5351-0554. nilvania@utfpr.edu.br
} 
O crescimento populacional influencia diretamente no processo de urbanização das cidades em todo o Brasil. Impulsionada pela industrialização, a malha urbana está cada vez mais adensada de loteamentos, ocasionando um desequilíbrio nas áreas urbanas públicas e verdes destinadas ao lazer, agravado pela falta de legislações específicas e, quando elas existem, de fiscalização.

O planejamento urbano contribui para a ordenação da ocupação do solo nas cidades, evitando que o meio ambiente seja modificado de forma inadequada. Para localizar uma urbanização estável, sustentável e economicamente correta, há vários requisitos que devem ser levados em consideração, os quais vão desde a topografia do local, localização do abastecimento de água e despejo de esgoto, escoamento das águas pluviais e um solo que permita o plantio de vegetação (MASCARÓ, 2010). Este procedimento urbanístico deve evitar priorizar os interesses individuais, a administração municipal deve buscar estratégias para atender à coletividade, levando em consideração a paisagem urbana e a infraestrutura existentes de acordo com as políticas de elaboração dos planos de desenvolvimento municipais.

Os espaços públicos urbanos contribuem para qualificar a paisagem, promover a recreação e o convívio social da população, além de propiciar, com sua vegetação, melhorias na condição microclimática por meio de ventilação e insolação do ambiente urbano. Mesmo, contudo, demonstrando a relevância e os benefícios das áreas verdes, órgãos públicos ainda resistem em reconhecer sua importância aos municípios. Na realidade, a vegetação urbana está perdendo espaço nas cidades (MASCARÓ; MASCARÓ, 2015).

As praças, no contexto de espaços públicos urbanos e legislações municipais, merecem atenção no que se refere ao planejamento, pois devem ser espaços livres, compostos de vegetação, áreas impermeáveis, edificações ou não que permitam o uso e acessibilidade a todo tipo de usuário. Da observação empírica dos espaços públicos de Francisco Beltrão é possível elaborar a hipótese de que muitos não atingem o planejado e se tornam vazios, a população deixa de frequentá-los porque não correspondem ao que se espera do mobiliário urbano quanto à iluminação, áreas verdes e sombreamento. Nesse sentido, quando bem planejadas, podem ser elementos de qualidade estética e integração do traçado urbano, contendo recursos paisagísticos e ambientais, podendo ser considerados locais de arborização, lazer e descanso. Nesse contexto, o presente artigo busca analisar a legislação municipal que ordena o parcelamento do solo urbano quanto a áreas verdes e praças no contexto urbano, levantar a localização das praças identificando a área (metragem) no mapa urbano das suas áreas verdes e por meio das áreas verdes e arborização identificadas elaborar uma referência para servir de conhecimento para novos programas de requalificação, em que a arborização possa ser mais explorada.

A primeira seção trata dos aspectos introdutórios, abordando o tema e os objetivos. A segunda versa sobre a revisão bibliográfica para elaborar os conceitos sobre o planejamento urbano, legislações, espaço público urbano e arborização que ocorrem na região sudoeste do Paraná, contribuindo assim para melhor entendimento sobre o tema de estudo. A terceira seção discorre sobre a metodologia utilizada para o desenvolvimento do trabalho a campo. O quarto tópico aborda os resultados e discussões e é por meio deles que serão atingidos os objetivos propostos para o presente artigo. 


\section{O PLANEJAMENTO URBANO}

Nos últimos anos o planejamento urbano tem sido tema de análise e discussões dos órgãos públicos nas cidades. Decorrente da expansão populacional, busca-se entender o seu desenvolvimento, suas características e as causas dos problemas resultantes da evolução acelerada. O planejamento urbano é uma estratégia de resolução de problemas presentes e direcionamento (ordem, orientação) para o desenvolvimento futuro e adequado dos espaços urbanos e está diretamente relacionado ao desenho urbano, pois por meio dos loteamentos, vias, ruas, espaços públicos e demais benefícios é que serão determinados os potenciais econômicos e sustentáveis de um vilarejo, uma cidade, ou município, pois esse cenário envolve também as paisagens, construções e grupos de prédios e o estabelecimento de estruturas e processos que facilitem um desenvolvimento bem-sucedido (COWAN, 2005).

Até o final do século 19 a legislação do parcelamento do solo não era cobrada pelo poder público e cabia aos urbanistas a responsabilidade de determinar o uso do solo urbano em seus projetos arquitetônicos e urbanísticos. Na vigência do Decreto-lei n. 58, de 10 de dezembro de 1937, não se regularizava os parcelamentos ilegais, priorizando a organização do espaço urbano e a qualidade dos loteamentos (FERNANDES, 1995). Apenas trazia garantia da venda e compra dos loteamentos por intermédio de informações de lotes, dimensões, áreas livres, etc. Esse cenário trouxe alterações ao meio ambiente e à paisagem urbana, comprometendo a preservação do uso do solo, a evolução histórica e seu desenvolvimento social e econômico.

A Lei Federal 6.766/79 abrange normas urbanísticas, sanitárias, civis e penais, a fim de disciplinar a ocupação do solo e o desenvolvimento urbano, bem como a tutela do interesse público coletivo adquirente dos lotes previstos e um determinado empreendimento.

A exiguidade de execuções de políticas públicas causou desequilíbrio social e econômico nas cidades brasileiras. Segundo dados do IBGE, em 1940 apenas 23,6\% da população vivia nas cidades; já no ano 2000 este percentual atingiu 81,2\%, mostrando o inchaço na malha urbana. O planejamento urbano tem a função de antecipar os problemas, desenvolvendo ações para solucioná-los por meio de objetivos ou metas a serem alcançados em um determinado tempo (CHIAVENATO, 1993). Por meio da observação das políticas públicas pode-se prever a distribuição da população e de atividades econômicas nos municípios evitando a agressão ao meio ambiente e ao solo urbano, bem como organizar a ocupação dos espaços públicos.

De uma forma geral, essa problemática é simplificada e "a" resposta para as soluções das questões urbanas está na "ponta da língua" de gestores políticos e da população em geral: "é a falta de planejamento urbano" (SOUZA, 2005).

O Estatuto da Cidade busca, por meio da política urbana, "ordenar o pleno desenvolvimento das funções sociais da cidade e da propriedade urbana", como diretrizes importantes ao desenvolvimento sustentável, à gestão democrática e ao planejamento do desenvolvimento das cidades. Para que haja o desenvolvimento de uma cidade, é necessário que o planejamento tome conhecimento antecipado sobre os meios naturais visando atender s necessidades da população. 
A cidade de Francisco Beltrão, no Paraná, dispõe do Plano Diretor (PDDFB) desde 1996, considerando que o município utilizava o Plano revisado de 2007. As leis federais exigem atualizações a cada dez anos; sendo assim, em 2016 iniciou-se a atualização, finalizada em 2018 com a aprovação da Câmara Municipal. Com o crescimento territorial urbano acelerado é importante manter o Plano Diretor atualizado para direcionar o desenvolvimento das cidades. Uma das atenções direcionadas na revisão relacionou-se às taxas de ocupação para construção de imóveis, obrigatoriedade do recolhimento e utilização de água de chuva com o uso de cisternas (reservatórios), a estruturação de lagoas secas para a infiltração da água pluvial nos novos loteamentos e a construção de novas avenidas para suportar o tráfego.

Relacionado ao meio ambiente e ao espaço público urbano, destacando para a paisagem urbana na cidade de Francisco Beltrão, a Lei Municipal no 3.360/2007 direciona tópicos importantes, como no Capítulo III, seção V artigos 56 e 58 sobre os espaços públicos. Ela concebe diretrizes para impulsionar a integração dos espaços públicos com o entorno, promovendo, junto aos órgãos competentes, os tratamentos urbanísticos e de infraestrutura adequados; otimizar o uso das áreas públicas para cumprimento das funções sociais da cidade; adequar o Código de Posturas, disciplinando as condições e os parâmetros para uso das áreas e espaços públicos por atividades, equipamentos, infraestrutura, mobiliário e outros elementos subordinados à melhoria da qualidade da paisagem urbana, ao interesse público, às funções sociais da cidade e às diretrizes deste Plano Diretor (FRANCISCO BELTRÃO, 2007).

A paisagem urbana na sua concepção de áreas verdes é apresentada na Lei Municipal 3760/2010, que institui o Projeto de Adoção de Praças, Parques, Áreas Verdes e Áreas de Lazer e Esportivas, denominado "Projeto Mais Verde", no qual qualquer pessoa jurídica ou física com sede ou domicílio no município de Francisco Beltrão poderá participar:

Art. 1ㅇ - Fica instituído o Projeto de Adoção de Praças, Parques, Áreas Verdes e Áreas de Lazer e Esportivas, denominado "MAIS VERDE" no âmbito do município de Francisco Beltrão, que terá, entre outros, os seguintes objetivos:

I - Promover a participação da sociedade civil organizada, das pessoas jurídicas e físicas na urbanização, nos cuidados e na manutenção das praças, parques, áreas verdes e áreas de lazer e esportivas do município, em conjunto com o poder público municipal;

II - Incentivar o uso das praças, parques, áreas verdes e áreas de lazer e esportivas pela população da região de abrangência;

III - Propiciar que pessoas físicas e grupos organizados da população elaborem projetos de utilização dos referidos equipamentos públicos, de modo a atender às diversas faixas de idade e necessidades especiais da população (FRANCISCO BELTRÃO, 2010).

Cabe ao poder Executivo municipal, porém, por intermédio do Departamento competente, elaborar os projetos das construções das praças, áreas verdes, lazer e esportivas ou aprovar as propostas desenvolvidas fora do Departamento, até sua fiscalização. Analisando ainda a política do meio ambiente relacionada aos espaços públicos e áreas verdes, o Decreto № 004/2011 regulamenta a Lei № 3.760, de 20 de outubro de 
2010, que "Estabelece normas e procedimentos para parcerias entre o poder público municipal e a sociedade, no que concerne à adoção de áreas verdes públicas Programa 'Projeto Mais Verde' que decreta”:

Art. 1․ O município de Francisco Beltrão realizará processo de CHAMAMENTO PÚBLICO para habilitação de pessoas físicas e pessoas jurídicas interessadas em participar do Programa "Projeto Mais Vede" de Adoção de áreas verdes públicas, visando a sua reforma e manutenção, assim entendidos os parques, praças, canteiros, jardins e outras áreas passíveis de ajardinamento.

Art. 2․ Os canteiros de ruas e avenidas poderão ser adotados por um ou mais interessados desde que atendidos os trechos mínimos estabelecidos pela Secretaria Municipal de Meio Ambiente, após manifestação favorável dos órgãos municipais competentes.

Art. 3‥ Fica constituída a Comissão de Análise para o Programa de Adoção de Áreas Verdes, com intuito de analisar, deliberar e realizar o processo de Chamamento Público já indicado no Art. 10 deste Decreto (FRANCISCO BELTRÃO, 2011).

Mesmo sendo o Plano Diretor Municipal o norteador para o desenvolvimento urbano, algumas leis devem ser consultadas a fim de completar as diretrizes. Entre elas está a Lei 12.587/12, conhecida como a Lei da Mobilidade Urbana, que tem como princípios a destacar, em seu artigo 5으, a acessibilidade universal; desenvolvimento sustentável das cidades, nas dimensões socioeconômicas e ambientais; equidade no uso do espaço público de circulação, vias e logradouros e eficiência, eficácia e efetividade na circulação urbana. Em seu artigo 70 , seus objetivos buscam promover acesso aos serviços básicos e equipamentos sociais; proporcionar melhoria das condições urbanas da população no que se refere à acessibilidade e à mobilidade; promover o desenvolvimento sustentável com a mitigação dos custos ambientais e socioeconômicos dos deslocamentos de pessoas e cargas nas cidades e consolidar a gestão democrática como instrumento e garantia da construção contínua do aprimoramento da mobilidade urbana.

As normativas relacionadas ao Instituto Ambiental do Paraná (IAP) priorizam as relações de distanciamento e porcentagens das construções ou espaços loteados às áreas de preservação, rios, sangas e nascentes de água naturais. Como exemplo, os distanciamentos isolados das edificações a um raio de 50 metros das nascentes de águas naturais com preservação nativa.

\section{A PAISAGEM URBANA: Espaços Públicos Urbanos e Arborização}

Com o objetivo de propor uma melhor organização dos espaços públicos é indispensável conhecer o modo de distribuição dos espaços livres na malha urbana e a acessibilidade aos espaços por parte da população a quem se destina. Ressalta-se que precisamos mudar a mentalidade e facilitar novas formas de viver o espaço público, inicialmente conhecendo as suas dimensões, atribuições, equipamentos e instalações, características do solo e vegetação para garantir a mobilidade, funcionalidade, segurança, comodidade e beleza.

Roberto Burle Marx (2004) assevera que a paisagem arquiteta o território em diferentes formas. Destacar desse conjunto certas áreas, certas "paisagens", às quais conferimos determinado significado estético, cultural, científico ou social. Tratar essas 
áreas como unidades isoladas poderá constituir uma medida funcional adequada com vistas a determinadas finalidades. A paisagem define uma civilização, pois se trata de um direcionamento à percepção, concepção e ação que aponta sentido à relação de uma sociedade com o espaço e com a natureza (BERQUE, 1998). Conclui-se a complexidade na concepção da paisagem urbana evidenciando a importância da análise para a criação e recriação dos espaços construídos ou não.

"O espaço púbico é o lugar da cidade de propriedade e domínio da administração pública, o qual responsabiliza ao Estado com o seu cuidado e garantia do direito universal da cidadania e a seu uso e usufruto" (ALOMÁ, 2013). Um dos principais obstáculos para a convivência em equilíbrio no espaço público urbano é a divergência do que ele representa para cada pessoa, pois o seu desempenho e apropriação estão ligados ao uso e às interações sociais nele realizados. $O$ espaço é mais bem apresentado na cidade pela configuração espacial e a preocupação da sociedade contemporânea está em analisar as potencialidades de cada local, buscando melhor direcionamento quanto às áreas de convívio social, lazer e esportivo, possibilitando intervenções que atendam à necessidade de cada espaço urbano.

Os espaços públicos são lugares de encontro do outro, do diferente, cujo ser dá sentido à democracia. Oferecem ao cidadão a possibilidade de usufruir de sua cidade por meio das práticas sociais, lazer, manifestações da vida urbana e consequentemente uma melhor habitabilidade do ambiente urbano, visando à finalidade "última" da sociedade, que é viver (YÁSIGI, 2000).

A arquitetura e o urbanismo têm buscado uma nova imagem aos espaços públicos resgatando as memórias das cidades mediante a requalificação das formas, configurações, organização espacial e a paisagem urbana, garantindo a interação, as relações sociais e os valores. Com o debate do desenvolvimento sustentável propiciado pela Agenda 21, várias cidades brasileiras refletiram sobre os espaços públicos urbanos, pois não há um molde para o padrão urbano e os projetos para o planejamento dos espaços não são mais apenas paisagísticos, mas direcionam a visibilidade e a circularidade.

As áreas verdes de uma cidade estão dispostas na paisagem de forma com o que é plantado ou mesmo existente de modo natural. As incluídas nas vias públicas muitas vezes são consideradas importantes, pois além da ornamentação e sombra podem ser destinadas à recreação e ao lazer pela população. O meio científico busca associar, mesmo não sendo referências, os termos "área verde, espaços/áreas livres, arborização urbana, verde urbano" ao equipamento urbano de lazer (BARGOS, 2010). Entre as atribuições urbanísticas estão as composições estéticas e as paisagísticas da cidade, nas quais se inclui a arborização.

Oliveira (1996) conceitua as áreas verdes como

[...] áreas permeáveis (sinônimo de áreas livres) públicas ou não, com cobertura vegetal predominantemente arbórea ou arbustiva (excluindo-se as árvores no leito das vias públicas) que apresentam funções potenciais capazes de proporcionar um microclima distinto, no ambiente urbano, em relação à luminosidade, temperatura, além de outros parâmetros associados ao bem-estar humano (funções de lazer) com significado ecológico em termos de estabilidade geomorfológica e amenização 
da poluição, e que suporte uma fauna urbana, principalmente aves, insetos e fauna do solo (funções ecológicas); representando também elementos esteticamente marcantes na paisagem (função estética).

Considerar a distribuição das áreas verdes no ambiente urbano nas questões de quantidade, qualidade e distribuição é importante para avaliar se estão atingindo os índices e de que forma se concentram nos espaços. A Organização Mundial da Saúde (OMS) recomenda um índice de $12 \mathrm{~m}^{2}$ de área verde por habitante, enquanto a Sociedade Brasileira de Arborização Urbana (SBAU) recomenda um índice de $15 \mathrm{~m}^{2}$ de área verde por habitante (SBAU,2016).

As áreas verdes podem ser definidas como uma categoria de espaço livre urbano de vegetação arbórea e arbustiva, onde pelo menos $70 \%$ da área seja permeável, de acesso público ou não, e que cumpram funções ecológicas, estéticas e de lazer (BARGOS; MATIAS, 2011).

Segundo Camargo (1989), a distância máxima de uma residência até uma praça ou parque deveria ser de 200 metros e o cálculo por habitante de área verde deveria seguir $19 \mathrm{~m}^{2} /$ habitante. Na cidade de Francisco Beltrão o loteador é obrigado a concluir a infraestrutura, além das vias e logradouros públicos, áreas verdes e institucionais conforme a Lei Municipal $n^{\circ} 4.617 / 2018$. Da área total do loteamento, o percentual de $40 \%$ (quarenta por cento) é destinado às áreas públicas, e, desse valor, 10\% (dez por cento) da soma total das áreas de todos os lotes para usos institucionais ou comunitários, $8 \%$ (oito por cento) para áreas verdes e o restante do percentual inclui vias de circulação.

Muitos planejadores esforçam-se em atingir um equilíbrio entre o desenho urbano e o urbanismo consciente, o urbanismo sustentável busca alternativas para novos estilos de vida, permitindo a sustentabilidade. Busca-se uma reflexão sobre a forma que se vive no espaço, trabalha e se diverte. A rua deve acomodar a diversidade de usos de solos e escolhas de mobilidade (FARR, 2013).

\section{ASPECTOS METODOLÓGICOS}

A metodologia utilizada para a análise e caracterização dos espaços públicos urbanos (praças) em Francisco Beltrão tem como base a localização das praças do município a partir de dados cadastrais municipais.

Para a realização da primeira etapa optou-se pela revisão bibliográfica, na qual buscou-se definir conceitos para a delimitação do tema em estudo. Posteriormente, foi realizado levantamento bibliográfico específico com a finalidade de proporcionar maior conhecimento sobre legislações municipais e nacionais e conceitos relacionadas aos espaços urbanos públicos, áreas verdes e arborização. Posteriormente à análise dos dados obtidos por meio da pesquisa documental, foi realizado o levantamento de dados dos mapas urbanos para compreender as áreas ocupadas pelos espaços públicos urbanos e a demarcação de suas áreas arborizadas. Com isso, foi possível comparar os dados obtidos mediante levantamento bibliográfico e índices de áreas verdes reais estabelecidos.

As praças (áreas destinadas ao lazer e à recreação) podem atingir um determinado público pela localização, atrativos que propõem equipamentos, atividades e lazer que possibilitam realizar. Para delimitação do presente artigo foram demarcadas no 
mapa urbano as áreas das praças, tendo conhecimento das distâncias entre elas em seus bairros e papéis que desempenham, levando em consideração sua área total e de vegetação.

Francisco Beltrão (Figura 1), município de importância para o sudoeste do Paraná, está disposto em uma área de $731,73 \mathrm{~km}^{2}$, em sua maioria voltada a atividades agrícolas. Segundo dados do Ipardes, a cidade está a $492 \mathrm{~km}$ da capital do Estado, Curitiba, e a 41,67 km da cidade de Pato Branco. A região sudoeste do Paraná conta com 37 municípios divididos em três sub-regiões: Capanema, Pato Branco e Francisco Beltrão.

Figura 1 - Foto aérea e mapa de localização do município de Francisco Beltrão-PR
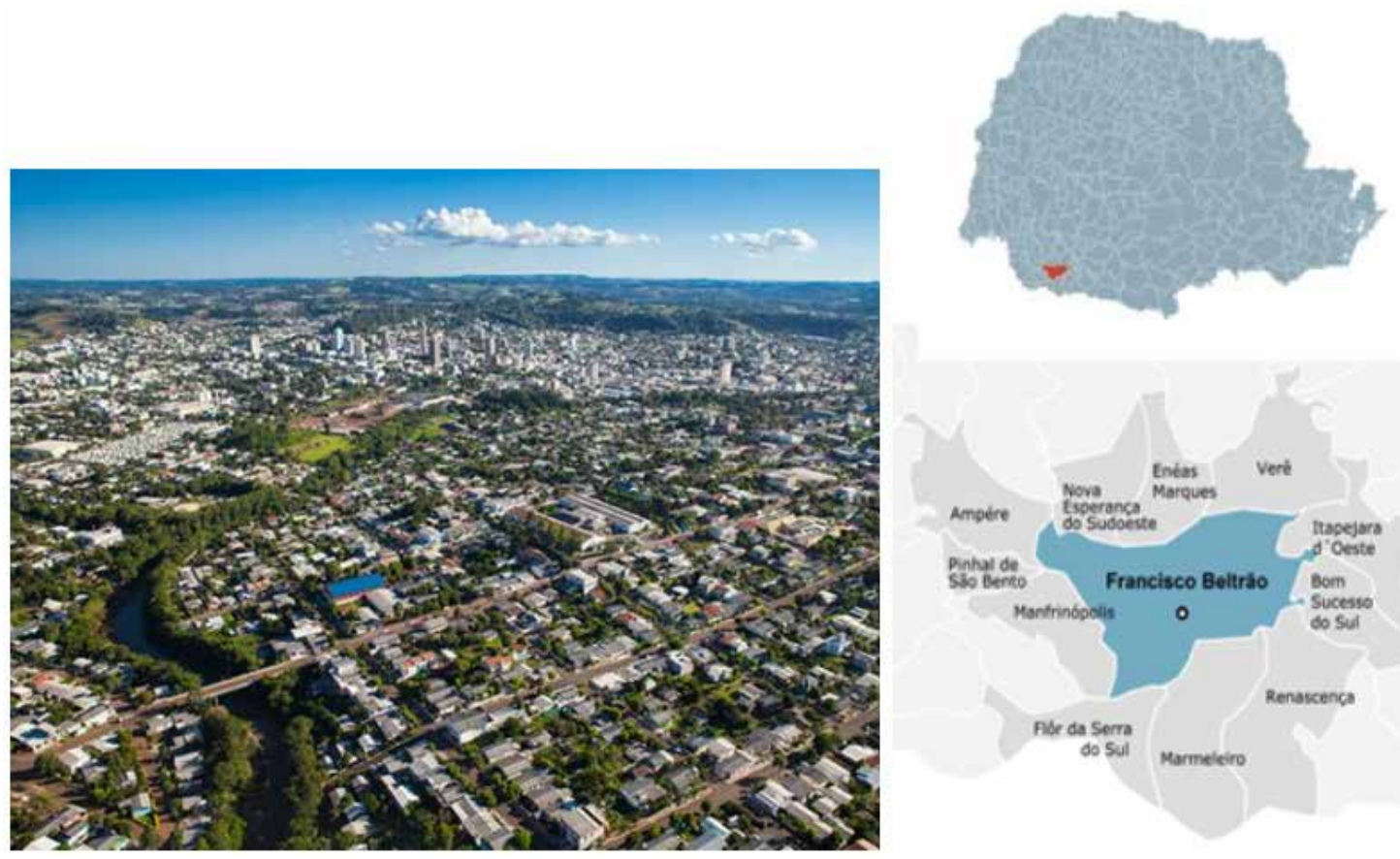

Fonte: Prefeitura de Francisco Beltrão-PR, IPARDES, 2018 (Organizado pela autora).

Francisco Beltrão tem 25 bairros e teve uma população estimada de 88.465 habitantes para o ano de 2017, com 90,1\% de domicílios urbanos em vias públicas com arborização (IBGE, 2017).

\section{RESULTADOS E DISCUSSÕES: As Praças de Francisco Beltrão/PR}

As praças, no contexto de espaços públicos urbanos e legislações municipais, merecem atenção no que se refere ao planejamento, pois podem ser espaços compostos de vegetação, áreas impermeáveis, edificações ou não, que permitam o uso e acessibilidade a todo tipo de usuário e identificando o espaço a ser inserido através da atuação dos gestores pela legislação municipal a praça pode melhorar as áreas de lazer e recreação propostas à comunidade para que se tornem atrativas e aprazíveis.

Francisco Beltrão possui, segundo dados da prefeitura, 18 praças em uma área $30.692,33 \mathrm{~m}^{2}$ e são classificadas em diferentes funcionalidades, porém não há um levantamento específico de sua classificação quanto ao índice de áreas verdes relaciona- 
das no quesito qualidade ambiental. A primeira praça foi marco no município em 1952, a Praça Eduardo Virmond Suplicy. Foi construída e inaugurada na gestão do prefeito Antônio de Paiva Cantelmo, em 1969. O nome escolhido é uma homenagem ao primeiro administrador da Colônia Agrícola Nacional General Osório (Cango), Eduardo Virmond Suplicy. A Praça recebeu obeliscos em homenagem aos pioneiros e uma cuia em tributo aos tradicionalistas.

A cidade de Francisco Beltrão, diferentemente de algumas capitais, não possui departamento específico para destinar atenção à conservação e planejamento de áreas verdes, espaços públicos como praças e parques, entretanto isso contribuiria para a proteção e manutenção de equipamentos públicos, áreas verdes, arborizações, programas relacionados ao meio ambiente, ao lazer e à recreação.

Percebe-se a necessidade de mudança da concepção dos gestores quanto aos espaços públicos urbanos dos municípios que ainda são vistos como lugares de gastos e de baixa prioridade quando comparados a outras necessidades, como saúde, segurança e bem-estar humano. Por esse motivo, foram identificados os bairros e neles a posição de cada praça, sua área inserida na malha urbana e o espaço destinado a áreas verdes por meio do estudo e análise de campo. As praças analisadas no município desempenham variadas funções, agregam valores e proporcionam melhor qualidade aos bairros em que estão inseridas. Poucas, no entanto, exercem com excelência os quesitos básicos levantados como áreas verdes, locais conservados, mobiliário urbano adequado e bem conservado, vegetação para sombreamento, acessibilidade, entre outros.

É notória, não apenas na cidade de Francisco Beltrão, mas em muitas cidades brasileiras, que a maior concentração das praças está nas áreas de população de média e alta renda e nos bairros mais antigos característicos ao desenvolvimento, como constatado no Bairro Centro, no qual o perfil imobiliário é de alto padrão, como é o caso da maior praça da cidade, a Praça Dr. Eduardo Virmond Suplicy, a qual possui uma morfologia quadrada de $7.700 \mathrm{~m}^{2}$ entre as principais vias e comércios, dispostas em áreas de lazer, recreação, monumentos, chafariz, feiras, palcos e calçadas (Figura 2). Com aproximadamente $4.500 \mathrm{~m}^{2}$ de área verde distribuídos em arbustos, árvores de pequeno, médio e grande porte, piso drenante, grama e generosa iluminação pública, é a praça com maior diversidade de vegetação e atividades.

Atualmente comporta playground, o acesso à Igreja Católica, estacionamentos, banca de revistas e feira do produtor rural, que também está no programa da praça. Com vegetação frondosa de grande porte há, distribuídos ao longo dos canteiros, espécies arbustivas e grama. 
Figura 2 - Instalação Praça Dr. Eduardo Virmond Suplicy

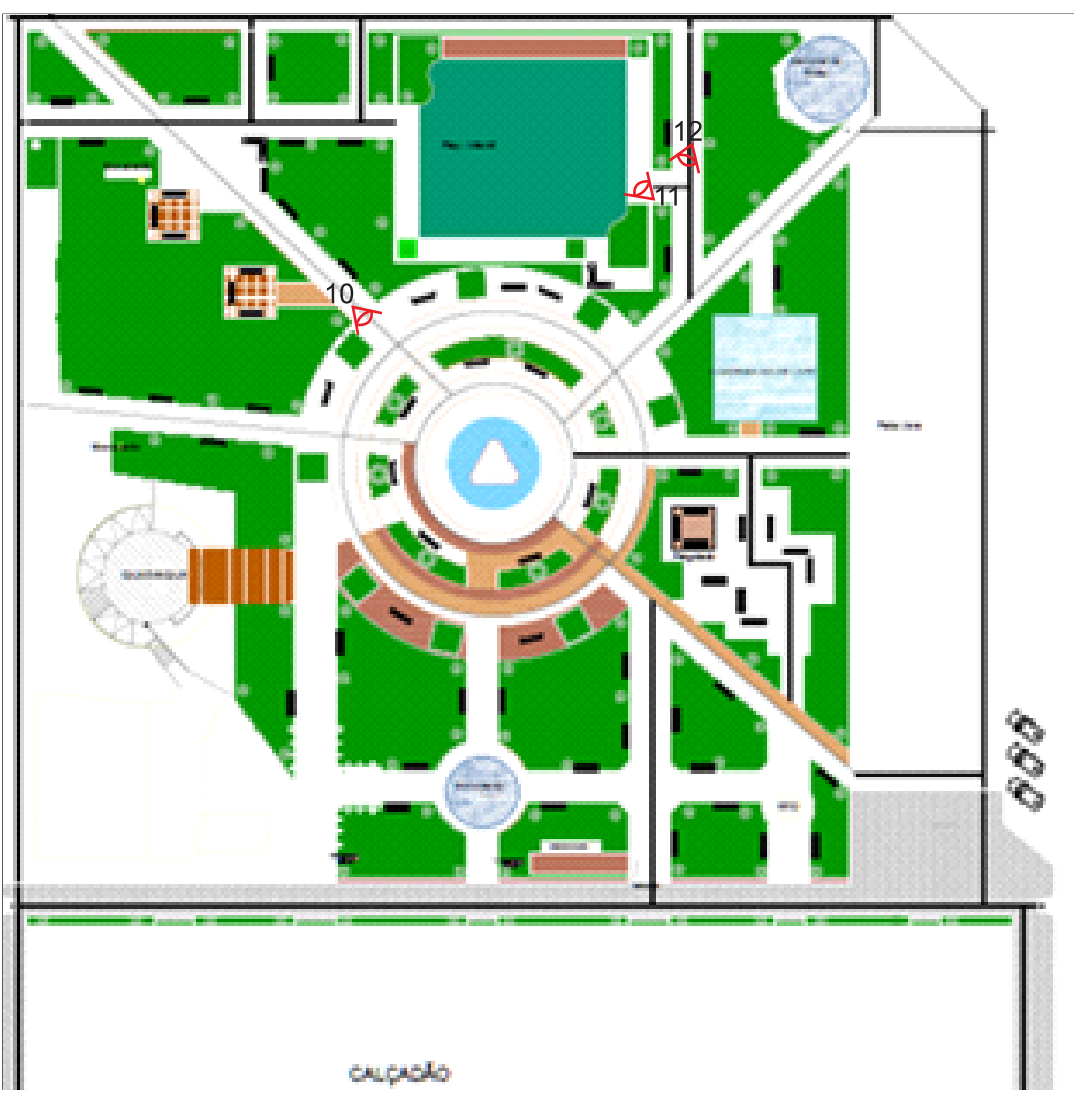

LEGENDA

ÁREA VERDE PLAYGROUND CHAFARZ MONUMENTOS QUIOSQUES

Fonte: As autoras.

A praça reflete qualidade de vida à comunidade, influenciando valores históricos e culturais, possui espécies variadas que contribuem para a aeração urbana e muito sombreamento, bem como circulações acessíveis de pedestres. Os valores funcionais são proporcionados pelo lazer urbano, fontes, feiras municipais e parquinhos para crianças (Fotografia 1 e 2).

Fotografia 1 - Vista geral da praça, playground

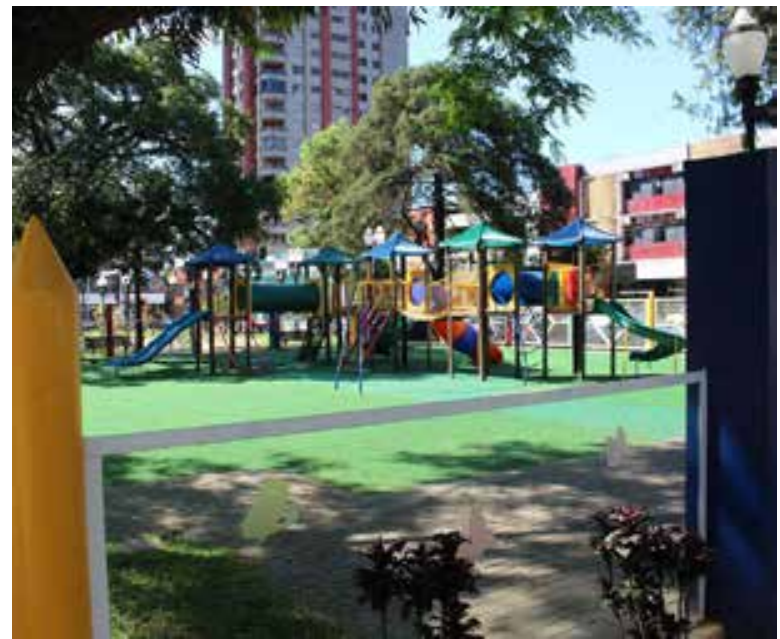

Fonte: Francisco Beltrão (2018a). 


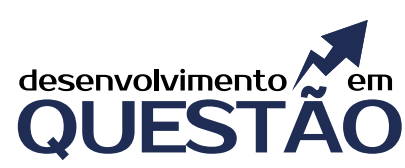

Fotografia 2 - Vista aérea espaços arborizados

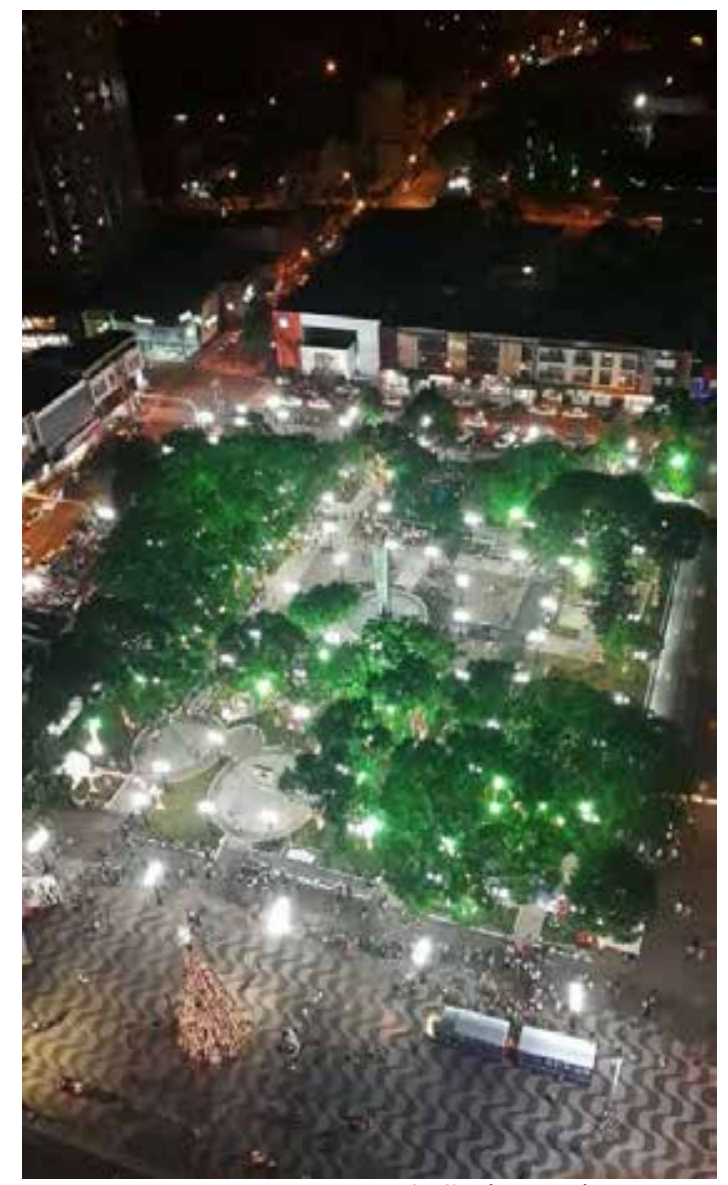

Fonte: Francisco Beltrão (2018a).

Uma análise geral das praças e muito preocupante foi que nem sempre elas suprem as necessidades de recreação, identidade do local, embelezamento, interação social e vizinhança e a instalação ligada à necessidade dos moradores e muito menos para assegurar saúde e vitalidade dos recursos ambientais ou benefícios a futuras gerações dos habitantes urbanos. No Mapa 1 é possível identificar a localização das praças de Francisco Beltrão concentradas na parte central da malha urbana, locais de desenvolvimento econômico acentuado.

Dos 25 bairros existentes, apenas 9 possuem praças públicas. A maioria (16 bairros) não as possuem, seja pelo fato de serem resultado de ocupação mais recente ou bairros ocupados pela população de baixa renda. Mesmo com a revisão recente do Plano Diretor Municipal, em 2018, não houve modificações direcionadas a áreas verdes e praças. Permanecem apenas os tópicos da Lei № 3.760/2010 que busca pelo Programa "Projeto Mais Verde" promover a participação da comunidade na manutenção, incentivar o uso e orientar projetos elaborados pela sociedade. Dados obtidos ao longo da pesquisa permitem inferir o desinteresse, mas não a obrigação de construir espaços e áreas destinadas para diferentes atividades nos novos bairros e loteamentos. Neles, o que prevalece são atividades direcionadas pelos gestores podendo atender à saúde, escolas, lazer, entre outros. 
Mapa 1 - Mapa da localização das praças de Francisco Beltrão, Paraná

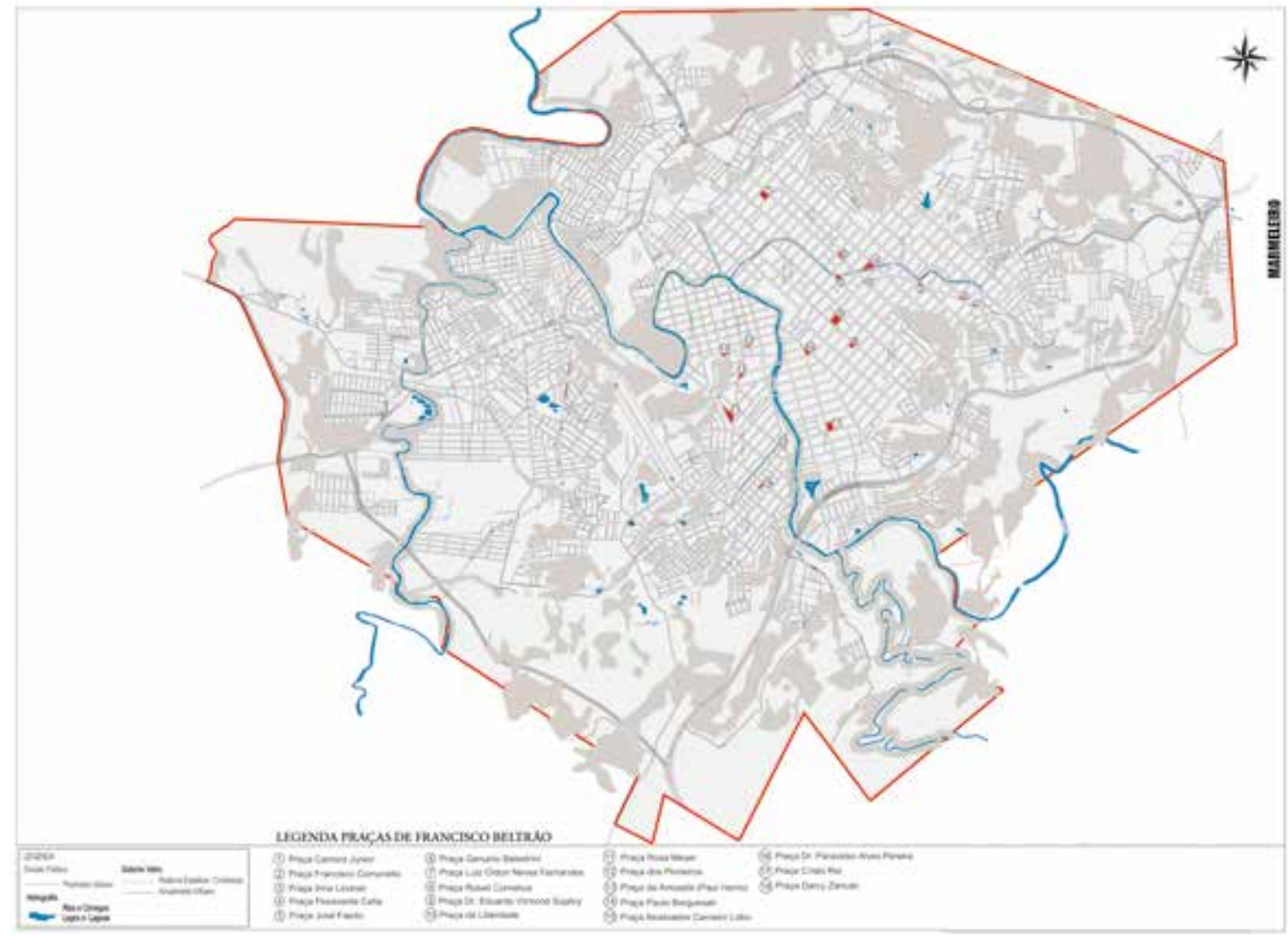

Fonte: A autora (2019).

Os resultados permitem certificar que a maioria das praças possui as mesmas classificações e que muitas não atingem o esperado quando relacionada a áreas verdes, conservação, qualidade ambiental e programas de necessidades direcionados ao lazer e bem-estar dos moradores. Provavelmente por estarem apenas inseridas na malha urbana, atendendo a soluções imediatas, mas não interagindo com a sociedade e a natureza. A praça, além da importância da quantidade, precisa ter qualidade.

As áreas verdes devem ser consideradas espaços livres, de vegetação arbórea e arbustiva, incluindo árvores que atendam e influenciem na qualidade ambiental, solos livres de edificações e acessibilidade a todos, lazer e funções que controlem a temperatura, poluição, abrigo da fauna, além de proporcionar valorização e beleza ao espaço. No Gráfico 1 é possível observar que a metragem $\left(\mathrm{m}^{2}\right)$ de área verde das praças analisadas é reduzida.

Em um total de $30.506,10 \mathrm{~m}^{2}$ de praças construídas e identificadas pela prefeitura, $14.574,93 \mathrm{~m}^{2}$, ou seja, $47,77 \%$ da área são destinadas a espaços verdes. Considerando o que explicita Camargo (1989), que evidencia que cada habitante deve ter $19 \mathrm{~m}^{2}$ de área verde, Francisco Beltrão destina para sua população, considerando a população estimada pelo IBGE de 2017, com as praças um total de $14.574,93 \mathrm{~m}^{2}$. Desse total sugerido pelo autor, as praças proporcionam aproximadamente $1 \%$ da área, deixando os demais percentuais para os parques, áreas livres e áreas de preservação. 


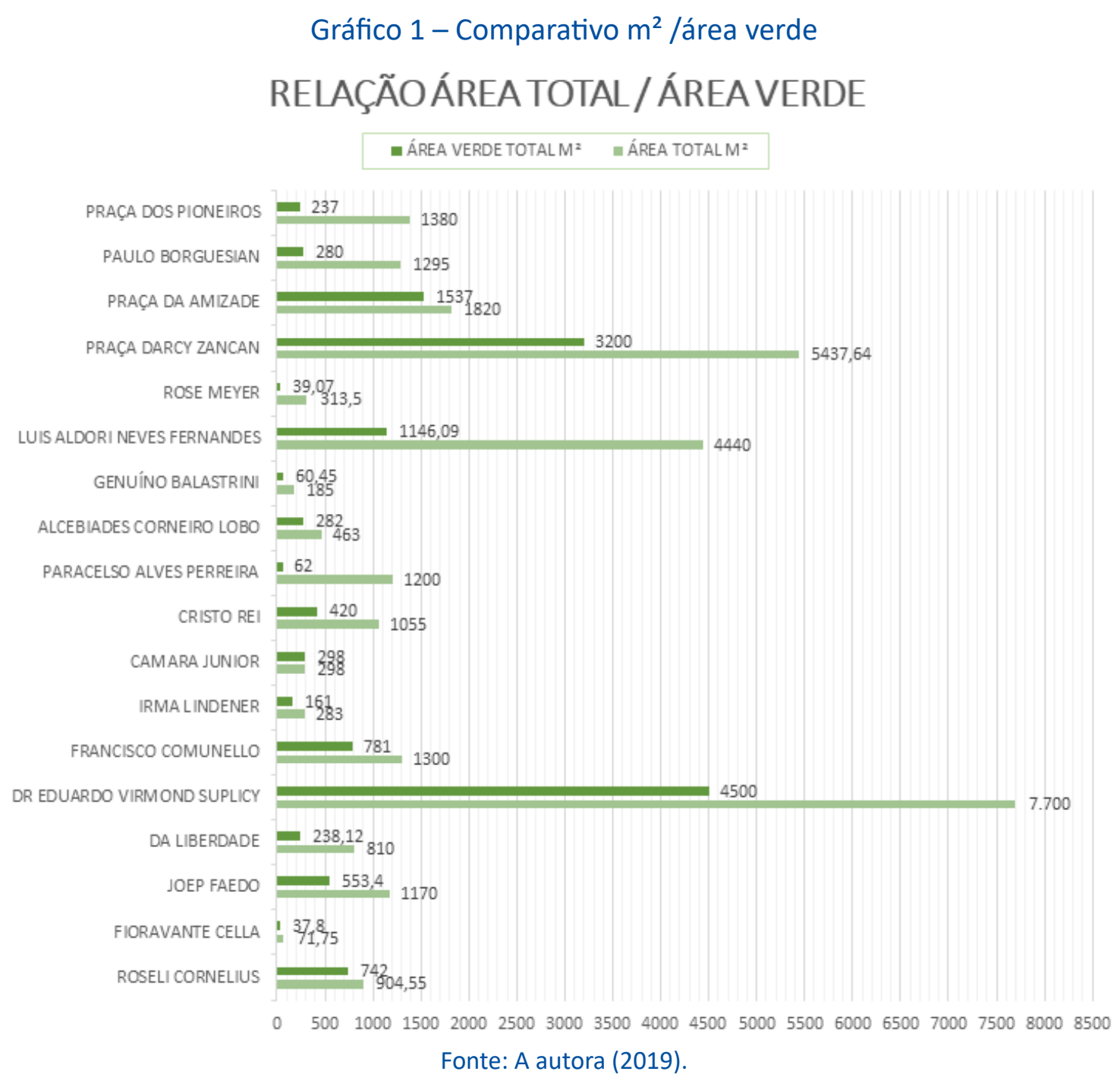

As praças analisadas na cidade de Francisco Beltrão, tendo como base o levantamento realizado, possui áreas reduzidas para ampliação ou criação de programas como áreas de lazer, recreação, locais de descanso e de vegetação. Como contribuição ao estudo, para haver uma requalificação das praças o município pode fazer uso dos vazios urbanos esquecidos ou não qualificados e potenciais pelo critério de proximidade sem edificação ou de até $20 \%$ de áreas edificada, nas possibilidades de inclusão de áreas as praças aumentando sua metragem para a inclusão de uma massa verde e arborizada, priorizando qualidade aos moradores.

Essa ferramenta pode contribuir para a qualidade da cidade, tornando-a mais organizada e ocupada de forma correta, prevalecendo as áreas verdes e de lazer apontadas como insatisfatória à população, pois atua como instrumento de minimização da segregação urbana de democratização do direito à cidade, ao uso do solo urbano e da melhoria da qualidade de vida.

\section{ALGUMAS CONSIDERAÇÕES-}

O crescente desenvolvimento das cidades sem planejamento e muitas vezes infraestrutura, tem deixado a malha urbana cada vez mais povoada. $O$ solo é preenchido por edificações, praças pavimentadas, calçadas, que consequentemente prejudicam a 
paisagem urbana, deixando esse cenário cada vez mais comprometido. Apesar da importância esses aspectos são muitas vezes esquecidos e apenas quando se torna problema entra em discussão.

$\mathrm{O}$ artigo aponta uma abordagem que permite identificar por meio das praças a importância da requalificação dos espaços existentes e planejamentos de viabilidade para novas, buscando atingir as necessidades da população quanto à área verde e lazer. Esse artigo propôs um percurso para discutir a apropriação das praças na cidade de Francisco Beltrão-PR, pois por muito tempo os projetos para os espaços públicos urbanos eram desenvolvidos de acordo com a percepção de planejadores e profissionais de Arquitetura.

Mesmo o Plano Diretor não contendo normativas às praças, as quais não atribuem exigências específicas à instalação de metragens mínimas, índices percentuais relacionados a áreas totais e programas de necessidades específicos por percentual de habitantes por bairros, bem como a forma acessível de inserção na malha urbana, demonstra a necessidade de informações relacionadas à concepção do projeto garantindo a qualidade desses locais que, por meio de normativas, fiscalização e pela requalificação, propõe-se ambientes mais saudáveis para a vida humana. No meio desse processo quem sofre consequências é a população, que carece de atividades de lazer, recreação e arborização.

Muitas das praças beltronenses, ainda que inseridas no contexto urbano de forma privilegiada em bairros centrais e próximas ao cotidiano da população, não são atrativas, pois além da carência de elementos naturais dispostos pela vegetação, não possuem infraestrutura como bancos, iluminação, equipamentos esportivos, entre outros. O local deve ser convidativo e além da beleza, ter utilidade. Foi possível apontar a necessidade de ações mais efetivas pelo poder público em relação às praças, uma vez que muitas encontram-se nas condições de vazios urbanos pela falta de atuação das leis municipais. Incluir novos espaços urbanos arborizados deve ser uma constante preocupação para gestores, cidadãos e profissionais da área para constituir ambientes mais saudáveis e propícios ao bem-estar humano, que são condições básicas para o alcance da qualidade ambiental urbana.

Diante desse contexto, percebe-se a necessidade de ampliar os estudos e pesquisas envolvendo essa temática, tendo por objetivo, entre outros, o desenvolvimento de ferramentas que possam, de uma maneira mais simples e direta, auxiliar a análise que antecede a aprovação de novos espaços públicos no que tange à transformação de vazios urbanos em espaços utilizáveis. Dessa forma, podemos concluir que determinados locais podem ser mapeados para o desenvolvimento de espaços urbanos públicos aproveitando totalmente ou não sua ocupação de formas diferenciadas, priorizando questões culturais e ambientais.

Entende-se que a cidade precisa crescer e se desenvolver, mas existem limites para esse crescimento e fica evidente a necessidade de avaliar cada espaço de forma particular, levando em consideração as características e os limites de seu espaço físico, pesando os benefícios e prejuízos decorrentes. 
Nesse contexto, para o município de Francisco Beltrão, a análise realizada mostrou que há possibilidades por meio da avaliação das áreas desenvolver propostas mais relevantes para a instalação de espaços públicos urbanos atendendo à necessidade de toda população, ampliando a expansão em bairros distantes, utilizando como sugestão os vazios urbanos não edificados.

Assim, fica claro que as características do município o colocam em uma situação que exige bastante atenção no momento de planejar, com o intuito de evitar maiores danos aos seus habitantes e ao ambiente natural que se refere ao uso territorial e à qualidade de vida. E para isso é preciso criar estratégias criativas de atração e desenvolvimento para que cada vez mais pessoas sintam-se confortáveis e à vontade para usar os espaços urbanos públicos.

\section{REFERÊNCIAS}

AGENDA 21. Conferência das Nações Unidas sobre Meio Ambiente e Desenvolvimento. Rio de Janeiro, 3 a 14 de junho de 2002.

ALOMÁ, P. R. O espaço público, esse protagonista da cidade. 2013. Tradução Gabriel Pedrotti. Disponível em: https://www.archdaily.com.br/br/01-162164/o-espaco-publico-esse-protagonista-da-cidade/. Acesso em: 15 mar. 2018.

BARGOS, D. C. Mapeamento e análise das áreas verdes urbanas como indicador da qualidade ambiental urbana: estudo de caso de Paulínia-SP. 2010. 147 f. Dissertação (Mestrado) - Universidade Estadual de Campinas, Curso de Geografia, Pós-Graduação em Geografia, Campinas, 2010.

BARGOS, D. C.; MATIAS, L. F. Áreas verdes urbanas: um estudo de revisão e proposta conceitual. Revsbau, Piracicaba, SP, v. 6, n. 3, 2011.

BERQUE, A. Paisagem-marca, paisagem-matriz: elementos da problemática para uma geografia cultural. In: CORRÊA, R. L.; ROSENDAHL, Z. Paisagem tempo e cultura. Rio de Janeiro. Ed. UFRJ, 1998.

CAMARGO, L. O. de L. O que é lazer. São Paulo: Brasiliense, 1989.

COWAN, R. The Dictionary of Urbanism, Streetwise Press, 2005. Diretrizes internacionais sobre Planejamento Urbano e regional. On-line. 2015. Disponível em: http://unhabitat.org/development-of-international-guidelines-on-urban-and-territorial-planning/. Acesso em: 10 out. 2017.

CHIAVENATO, I. Introdução à Teoria Geral da Administração. 4. ed. São Paulo: Makron Books, 1993.

FARR, D. Urbanismo sustentável - desenho urbano com a natureza. Porto Alegre: Bookman, 2013.

FERNANDES, E. Law and urban change in Brazil. London: Avebury, 1995.

ITU-T Focus Group on Smart Sustainable Citeis (FG-SSC). Disponível em: http://oemmndcbldboiebfnladdacbdfmadadm/https://journals.sagepub.com/doi/pdf. Acesso em: 7 jan. 2018.

FRANCISCO BELTRÃO (município). Decreto № 004/2011 regulamenta a Lei № 3.760 de 20 de outubro de 2010. Projeto Mais Verde. 2011. Francisco Beltrão, PR, 20 out. 2010. p. 1-2. Disponível em: http://www. franciscobeltrao.pr.gov.br/legislacao/categoria/decretos?ano=2011.

FRANCISCO BELTRÃO (município). Aspectos turísticos. Disponível em: http://www.franciscobeltrao.pr. gov.br/departamentos/turismo/pontos-turisticos/praca-eduardo-virmond-suplicy-e-o-calcadao-central/. Acesso em: 27 fev. $2018 \mathrm{a}$.

FRANCISCO BELTRÃO (município). Mapa dos bairros da municipal. Francisco Beltrão: Secretaria Municipal de Planejamento, 2017a.

FRANCISCO BELTRÃO (município). Lei no 3360/2007, de 25 de junho de 2007. Código Ambiental. Francisco Beltrão, PR, 25 jun. 2007. p. 1-15. Disponível em: http://franciscobeltrao.pr.gov.br/wp-content/uploads/2013/08/meioambiente.pdf. Acesso em: 14 jul. 2017.

FRANCISCO BELTRÃO (município). Lei no 3760/2010, de 20 de outubro de 2010. Projeto Mais Verde. Francisco Beltrão, PR, 20 out. 2010. p. 1-4. Disponível em: http://www.franciscobeltrao.pr.gov.br/legislacao/ lei-no-37602010/. Acesso em: 14 jul. 2017.

FRANCISCO BELTRÃO (município). Lei no 4.595/2018, de 18 de outubro de 2018. Trata do Conselho da Cidade de Francisco Beltrão, 2018b.

FRANCISCO BELTRÃO (município). Lei no 4.617/2018, de 13 de novembro de 2018. Parcelamento e uso do solo do município de Francisco Beltrão. Francisco Beltrão, 2018c. 
FRANCISCO BELTRÃO (município). Mapa dos bairros da municipal. Francisco Beltrão: Secretaria Municipal de Planejamento, 2017b.

IBGE. Instituto Brasileiro de Geografia e Estatística. Disponível em: https://www.ibge.gov.br/. Acesso em: 12 dez. 2017.

IPARDES. Instituto Paranaense de Desenvolvimento Econômico e Social. Disponível em: http://www.ipardes.gov.br/perfil_municipal/MontaPerfil.php?codlocal=139\&btOk=ok. Acesso em: 12 jan. 2018.

MARX, B. Arte, ciência e paisagismo. In: TABACOW, José. Roberto Burle Marx: arte e paisagem. São Paulo: Studio Nobel, 2004.

MASCARÓ, J. L. Sustentabilidade em urbanizações de pequeno porte. Porto Alegre: Masquatro Editora, 2010. p. 165.

MASCARÓ, L; MASCARÓ, J. Vegetação urbana. Porto Alegre. 4. ed. Masquatro Editora, 2015.

OLIVEIRA, C. H. Planejamento ambiental na cidade de São Carlos (SP) com ênfase nas áreas públicas e áreas verdes: diagnóstico e propostas. 1996. Dissertação (Mestrado em Ecologia e Recursos Naturais) Universidade Federal de São Carlos, São Carlos, SP, 1996.

SBAU. Sociedade Brasileira De Urbanização. Arborização brasileira. 2016. Disponível em: http://www. sbau.org.br. Acesso em: 4 out. 2017.

SOUZA, Marcelo. ABC do desenvolvimento urbano. 2, ed. Rio de Janeiro: Bertrand. Brasil, 2005.

YÁSIGI, E. O mundo das calçadas. Por uma política democrática de espaços públicos. São Paulo: USP-FFLCH+ Imprensa Oficial, 2000. Disponível em: http://www.revistas.usp.br/cadernosdecampo/article/ view/52448/56442. Acesso em: 10 jun. 2018. 